\title{
Platinum-based organometallic folders for the recognition of electron deficient aromatic substrates
}

\author{
Daniel Nuevo, ${ }^{[a]}$ Sergio Gonell, ${ }^{[a],[b]}$ Macarena Poyatos ${ }^{[a]}$ and Eduardo Peris ${ }^{\star[a]}$
}

process that is often referred to as coordination-driven selfassembly, ${ }^{[2 b, 3 c, 9,4]}$ and for this reason metallosupramolecules are often referred to as supramolecular assemblies. The resulting products display highly symmetric structures with well-defined

Abstract: A series of platinum complexes with cis-oriented polyaromatic $\mathrm{N}$-heterocyclic carbene ligands were prepared and characterized. The relative disposition of the polyaromatic ligands about the metal make these compounds to behave as a metallofolder, with a cavity defined by the void space between the polyaromatic functionalities. The complexes were used as receptors of organic molecules, where they showed selective affinity for binding electrondeficient aromatic substrates, such as 1,2,4,5-tetracyanobenzene (TCNB), 2,4,7-trinitro-9-fluorenone (TNFLU) and 1,4,5,8naphtalenetetracarboxylic dianhydride (NTCDA). The binding affinities of two of the metallofolders with these substrates were determined by means of ${ }^{1} \mathrm{H}$ NMR titrations. Electrospay mass spectrometry (ESI-MS) was also used to assess the affinities. The molecular structure of one of the platinum folders was determined in the presence of TCNB, showing the clear interaction between this guest molecule and the folder formed by the two mutually cis polyaromatic ligands. This work demonstrates how the presence of the mutually cis polyaromatic ligands may constitute a very useful tool for the preparation of metal-based receptors.

\section{Introduction}

Metallosupramolecular chemistry was defined by Constable in 1994 as the chemistry involving the combination of bridging organic ligands with metal units to synthesize discrete or polymeric assemblies. ${ }^{[1]}$ Hence the basis for metallosupramolecular design is the availability of (often rigid) ligands with two or more binding sites that must be able to combine with suitable metal fragments to form symmetrical structures with a variety of shapes and sizes. ${ }^{[2]}$ The two most commonly used strategies for metallosupramolecular design are the directional bonding and symmetry interactions, ${ }^{[3]}$ and they both rely on the combination of polytopic rigid ligands and metal fragments with available coordination sites. The mixing of soluble metal and ligand precursors spontaneously form metal-ligand bonds that generate the thermodynamically favored products in a

[a] D. Nuevo, Dr. M. Poyatos, Prof. E. Peris Institute of Advanced Materials (INAM). Universitat Jaume I. Av. Vicente Sos Baynat s/n. Castellón. E-1271. Spain. Email: eperis@uji.es

[b] Dr. S. Gonell

Current address: Homogeneous, Supramolecular and Bio-Inspired Catalysis, Van 't Hoff Institute for Molecular Sciences, University of Amsterdam, Science Park 904, Amsterdam 1098XH, The Netherlands.

Supporting information for this article is given via a link at the end of the document. cavities, ${ }^{[5]}$ which impart unique reactivity with applications in catalysis, ${ }^{[6]}$ molecular recognition ${ }^{[7]}$ and also for the stabilization of highly reactive species. ${ }^{[8]}$ Most efforts in the design of metallosupramolecules are based on mimicking enzymes, and hence well-defined hydrophobic cavities are pursued, but again, the design of biomimetic complexes relies on the synthesis of metal complexes with polydentate ligands that mimic the environment found in nature.$^{[9]}$ For the formation of the cavities an array of several metals is needed, and this is the reason why metallorganic molecules with cavities (metallocavitands) have been defined as 'multimetallic complexes where the metal coordination is necessary for cavity formation. ${ }^{[5 b]}$ Therefore, by definition, metallocavitands bearing only one metal are rare, and mostly refer to metallo-based tweezers. ${ }^{[10]}$

We recently described a series of $\mathrm{N}$-heterocyclic carbene-based cylinder-like structures with hollow central cavities, which were prepared by metal controlled self-assembly methodology. ${ }^{[1]}$ Parallel to this research, we also designed a series of di- and tritopic $\mathrm{N}$-heterocyclic carbene ligands ( $\mathrm{NHCs}$ ) bearing rigid polyaromatic linkers, ${ }^{[12]}$ and found that the catalytic performances of their metal complexes derived were highly influenced by supramolecular effects, which we attributed to the $\pi-\pi$ stacking interactions between the polyaromatic spacers of the ligands and the aromatic substrates. ${ }^{[13]}$ For the study of the nature of these supramolecular interactions, a series of complexes with monodentate NHC ligands with rigid polyaromatic backbones were obtained ${ }^{[14]}$ and, by using well-known host-guest chemistry approaches, we were able to determine the nature of the supramolecular interaction and also quantify the extent of the noncovalent binding. ${ }^{[14 \mathrm{~b}]}$ The binding-affinities that we found between the $\pi$-stacking additives and the metal complexes were low, ${ }^{[12 d,}$ ${ }^{14 b]}$ because the host-guest interactions were produced on the open surface of the metal complex, rather than in the interior of a cavity. From our point of view, these results established the basis for the use of monometallic complexes as receptors for molecular recognition, as an alternative to the use of the ubiquitous selfassembly polymetallic architectures. We thought that we could improve the binding affinities (and thus the properties as receptors) of monometallic compounds by building a well-defined pocket by cis-coordinating two polyaromatic-based ligands to a pseudo-square planar metal complex (Scheme 1). The resulting folder-shaped complex, or organometallic folder (OMFO), should show enhanced recognizing abilities by displaying a cavity defined by the two mutually cis large polyaromatic ligands. 


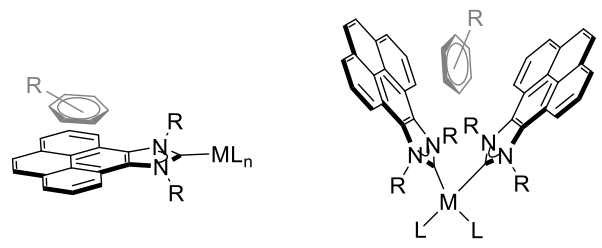

Organometallic Folder (OMFO)

Scheme 1. Two systems with polyaromatic NHC ligands

We herein describe a family of cis-platinum (II) complexes with pyrene- and phenanthrophenazine-NHC ligands, which we used as receptors for a series of organic molecules, and demonstrate how the presence of the mutually cis polyaromatic ligands constitutes a very useful tool for the preparation of metal-based receptors. The nature of the host-guest interaction and the association constants were obtained by ${ }^{1} \mathrm{H}$ NMR titrations.

\section{Results and Discussion}

The types of molecules that we prepared in this work contain a platinum center with two cis $\mathrm{NHC}$ ligands decorated with a pyrene or a phenanthrophenazine fragment. The resulting molecules, display a folder-type structure, with the two NHC ligands functionalized with the rigid polyaromatic fragment defining a void space. The depth of the folder is defined by the nature of the polyaromatic ligand, being deeper for the case of the phenanthrophenazine substituted imidazolylidene. The pyreneimidazolium salts $1-\mathrm{R}(\mathrm{R}=\mathrm{Et}, n \mathrm{Pr}$ and $n \mathrm{Bu})$ were obtained according to the method that we previously described for 1-Me. ${ }^{[15]}$ The reaction of $1-\mathrm{R}$ with cis- $\left[\mathrm{Pt}(\mathrm{CCPh})_{2}(\mathrm{COD})\right](\mathrm{CCPh}=$ phenylacetylide, $\mathrm{COD}=1,5$-cyclooctadiene) in the presence of a base (see Scheme 2) in THF, afforded the cis-pyrene-NHC Pt(II) complexes 2-Me, 2-Et, 2-nPr and 2-nBu in moderate to excellent yields.

Complexes 2-R were characterized by NMR spectroscopy, Mass Spectrometry (ESI-MS) and gave satisfactory elemental analyses. The NMR spectra of all three complexes were consistent with the twofold symmetry of the molecules. The ${ }^{13} \mathrm{C}$ NMR spectra showed the diagnostic signal due to the presence of the metallated carbene carbons at $178.1,178.1,178.6$ and $178.3 \mathrm{ppm}$, and the signals due to the metallated carbons of the acetylide appeared at 107.2, 107.7, 106.9 and $106.9 \mathrm{ppm}$ for 2-Me, 2-Et, 2-nPr and 2- $n \mathrm{Bu}$, respectively.

By using the same synthetic protocol, but using the phenanthro[4,5-abc]phenazine-imidazolyum salt 3-nBu, complex 4- $n \mathrm{Bu}$ was obtained in $45 \%$ yield. The NMR spectra of the complex were consistent with its binary symmetry. The ${ }^{13} \mathrm{C}$ NMR spectrum showed the signal due to the magnetically equivalent carbene carbons at $190.5 \mathrm{ppm}$. The electrospray mass spectrum of the complex displayed a peak at $\mathrm{m} / \mathrm{z} 1333.6$, attributed to $[\mathrm{M}+\mathrm{Na}]^{+}$.

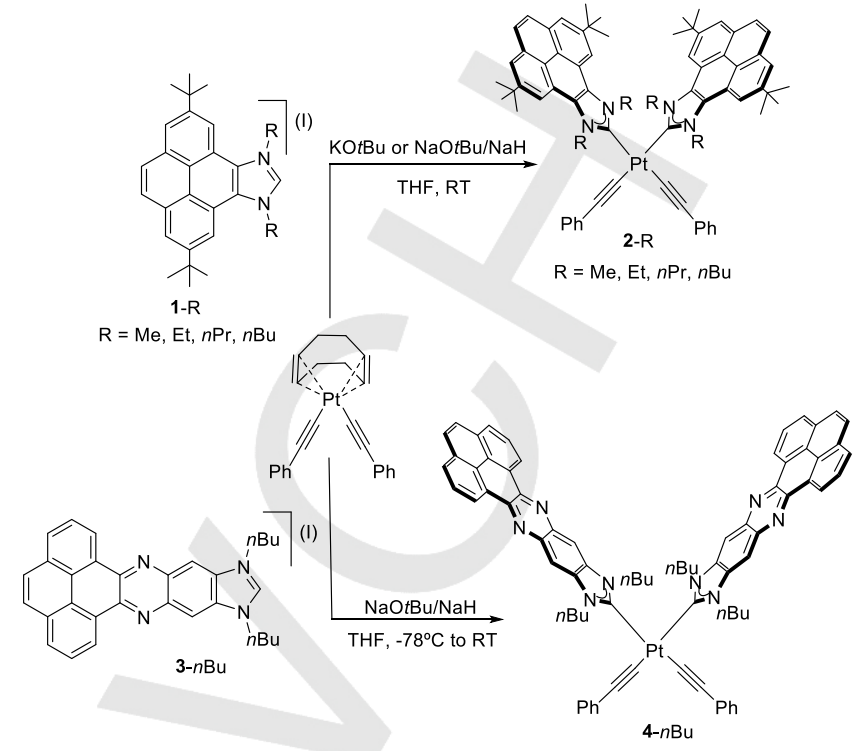

Scheme 2. Synthesis of complexes.

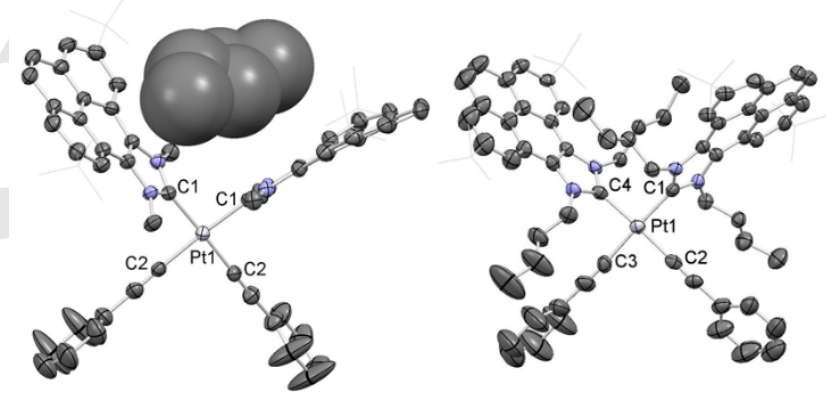

Figure 1. Molecular structures of complexes 2-Me (left) and 2-nBu (right) Ellipsoids at $50 \%$ of probability. Tert-butyl groups shown as wireframes. Hydrogen atoms omitted for clarity. In 2-Me two molecules of $\mathrm{CHCl}_{3}$ omitted, and hexane is represented in the space-filling diagram. Selected bond distances $(\AA)$ and angles $\left({ }^{\circ}\right)$ for 2-Me: $\mathrm{Pt}(1)-\mathrm{C}(1)$ 2.041(4), $\mathrm{Pt}(1)-\mathrm{C}(2)$ 2.031(5), $\mathrm{C}(2)-\mathrm{C}(3)$ 1.163(7), C(1)-Pt(1)-C(1) 92.8(2), C(2)-Pt(1)-C(2) 89.4(3). For 2-nBu: Pt(1)-C(1) 2.048(4), Pt(1)-C(4) 2.027(4), Pt(1)-C(2) 2.016(5), Pt(1)-C(3) 2.037(5), C(1)$\mathrm{Pt}(1)-\mathrm{C}(4)$ 92.00(16), C(2)-Pt(1)-C(3) 86.99 (17)

The molecular structure of 2-Me was confirmed by single crystal $X$-ray diffractometry (Figure 1, left). The molecule consists of a platinum center with two pyrene-imidazolylidene ligands and two phenylacetylides in a cis disposition. The two pyreneimidazolylidenes and the two phenylacetylides are symmetry related. The Pt-C(carbene) bond distance is 2.041 (4) $\AA$. The angle formed by the imidazolylidene ring and the metal coordination plane is $66.95^{\circ}$, thus far from being perpendicular. The pyrene fragments of the carbene ligands show a bow-shaped distorsion, with their concave sides looking at each other. Interestingly, one molecule of hexane occupies the cavity formed by the two pyreneimidazolylidene ligands, indicating that the pocket generated by the two pyrene-based ligands trends to not remain void, and therefore suggesting that this folder-type molecule may be used as host in the recognition of selected organic molecules. This structure can be compared with the molecular structure of complex $2-n \mathrm{Bu}$ (Figure 1, right). In this case, the average angle established between the pyrene- 
imidazolylidene ligands and the coordination plane is $66.92^{\circ}$, very similar to that found in 2-Me. The Pt-C (carbene) bond distances are 2.027(4) and 2.048(4) $\AA$. Interestingly, the folder formed by the two pyrene-imidazolylidene ligands is not trapping any solvent molecule, but it does not remain empty, because two $\mathrm{N}-n \mathrm{Bu}$ wingtips from each of the imidazolylidene ligands are occupying the void space of the cavity.

The ${ }^{1} \mathrm{H}$ NMR spectra of 2-Me and 2- $n \mathrm{Bu}$, were recorded in $\mathrm{CDCl}_{3}$, $\mathrm{C}_{6} \mathrm{D}_{6}$ and DMSO- $d_{6}$. The ${ }^{1} \mathrm{H}$ NMR spectra of 2-Me were concentration dependent in $\mathrm{CDCl}_{3}$ and $\mathrm{C}_{6} \mathrm{D}_{6}$. As the concentration of the complex increased, the signals associated to the protons of the pyrene ring were upfield shifted, and those related to the phenyl ring of the phenylacetylide ligand were downfield shifted, as a consequence of the formation of self-associated assemblies. Plotting the chemical shift changes versus the concentration of the complexes allowed us to very accurately calculate the dimerization constants, as shown by the very low residual distribution of the data fitting. These constants were 40 and 3900 $\mathrm{M}^{-1}$, for the dimerization of 2-Me in $\mathrm{CDCl}_{3}$ and $\mathrm{C}_{6} \mathrm{D}_{6}$, respectively (see Supplementary Information for more details). These results suggest that the association constants decrease with the polarity of the solvent, in the order $\mathrm{C}_{6} \mathrm{D}_{6}>\mathrm{CDCl}_{3}>\mathrm{DMSO}-d_{6}$, as an indication of the higher solvating abilities of the polar solvents with the planar electro-rich surfaces of the pyrene-functionalized complex. This affinity by the polar molecules of the solvent with the complexes is also reflected by the mass spectra of DMSO solutions of complexes 2-Me and $2-n \mathrm{Bu}$, which in all cases displayed intense peaks assigned to $[\mathrm{M}+\mathrm{DMSO}+\mathrm{Na}]^{+}$. For the case of 2-nBu, we observed that the ${ }^{1} \mathrm{H}$ NMR spectra did not show concentration dependence in any of the three solvents used, therefore suggesting that for this complex self-association is negligible.

We thought that the pyrene fragments in complexes 2-Me, 2-nBu and 4- $n \mathrm{Bu}$, should provide an electron-rich environment that could be used for the recognition of electron-deficient aromatic guests. Since the two metal complexes with the $n \mathrm{Bu}$ substituents were the ones to show less tendency to self-associate, we considered $2-n \mathrm{Bu}$ and $4-n \mathrm{Bu}$ to be the best host choices. The aromatic guests that we chose for our study were 1,2,4,5tetracyanobenzene (TCNB), 2,4,7-trinitro-9-fluorenone (TNFLU) and 1,4,5,8-naphtalenetetracarboxylic dianhydride (NTCDA) (Scheme 3). For the titrations we chose DMSO- $\mathrm{d}_{6}$ as the optimum solvent, because it provided the highest solubility of all guests used. TNFLU is also very soluble in chloroform, thus for this guest we also performed the titration in $\mathrm{CDCl}_{3}$ in order to compare the result with the one obtained in DMSO- $d_{6}$.<smiles>N#Cc1cc(C#N)c(N)cc1N</smiles><smiles>O=C1OC(=O)c2ccc3c4c(ccc1c24)C(=O)OC3=O</smiles><smiles>O=C1C2=Cc3cc([N+](=O)[O-])ccc3C2=C([N+](=O)[O-])C=C1[N+](=O)[O-]</smiles>

Scheme 3. Electron-deficient aromatic guests used in this study
Some interesting features about the structures of the host-guest complexes formed could be directly extracted from the ${ }^{1} \mathrm{H}$ NMR spectra taken from our titration experiments. Figure 2 shows some representative spectra of the titration of 4-nBu with TNFLU in $\mathrm{CDCl}_{3}$. As can be seen from the series of spectra, the addition of the guest was accompanied by an upfield shift of the signals due to the protons of the phenanthro-phenazine fragment of the $\mathrm{NHC}$ ligand ( $a, b, c, d$ and e), while the signals due to the protons of the phenylacetylide remained unchanged. A maximum negative shift of $0.26 \mathrm{ppm}$ was achieved for the case of proton a. This result is consistent with the guest interacting with the polyaromatic fragments of the NHC ligands by the inner cavity of the metallofolder, rather than with the phenyl ring of the phenylacetylide. A $\pi-\pi$ stacking interaction between the polyaromatic moiety of the NHC ligand and the molecule of TNFLU would be the driving force for the encapsulation. Similar structural conclusions could be obtained for the titrations with all other guests, and for the titrations using complex 2-nBu.

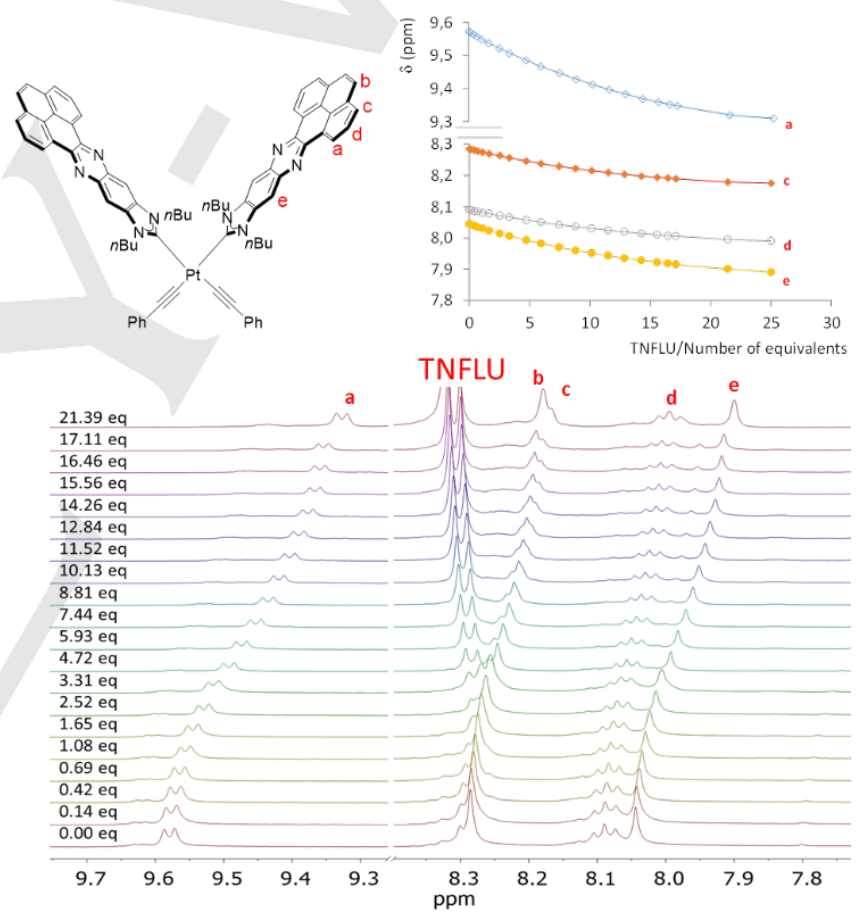

Figure 2. Representative region of the ${ }^{1} \mathrm{H}$ NMR $(500 \mathrm{MHz})$ spectra of the titration of 4-nBu with TNFLU in $\mathrm{CDCl}_{3}$. The spectra were recorded at a constant concentration of $4-n \mathrm{Bu}(1 \mathrm{mM})$ at $298 \mathrm{~K}$. The inset plot represents the binding isotherms.

Analysis of the ${ }^{1} \mathrm{H}$ NMR titrations allowed determining the stoichiometry of the host:guest adducts formed, and their association constants $\left(K_{a}\right) \cdot{ }^{[16]}$ The analysis of the binding isotherms showed that the curves were best fitted to the formation of 1:1 complexes. This conclusion was also supported by the fact that the fittings to a 1:1 stoichiometry gave the lowest residuals compared to other potential stoichiometries. The 1:1 association constants, $\mathrm{K}_{11}$, were calculated by global nonlinear regression analysis by simultaneously including all protons showing chemical 
shift variations. ${ }^{[16 a, 17]}$ The association constants that we obtained are shown in Table 1. In most cases the titrations were performed in DMSO- $d_{6}$, where the guests showed higher solubility. Only in the case of the titration of TNFLU, the experiments could also be carried out in $\mathrm{CDCl}_{3}$ due to its higher solubility. For the titration of 4- $n \mathrm{Bu}$ with TCNB in DMSO, the chemical shift variations were so low $\left(\Delta \delta_{\max } \approx 0.04 \mathrm{ppm}\right)$ that we could not determine an accurate value of the association constant. The association constants were higher in $\mathrm{CDCl}_{3}$ than in $\mathrm{DMSO}-\mathrm{d}_{6}$, in agreement with the higher solvating abilities of DMSO with the electron-rich surfaces of the ligands in 2- $n \mathrm{Bu}$ and 4- $n \mathrm{Bu}$ (compare entries 2 and 3 for titrations with TNFLU). As can be seen from the results, both $2-n B u$ and 4$n \mathrm{Bu}$ show low to moderate affinities for electron deficient aromatic substrates $\left(1 \mathrm{M}^{-1}>\mathrm{K}_{11}>22 \mathrm{M}^{-1}\right)$, while not showing any tendency to bind an electron-rich polyaromatic substrate such as pyrene. The metallofolder with a larger cavity, 4-nBu, consistently leads to higher binding constants. Among the electron deficient substrates, TNFLU gave the highest association constants for both complexes under study, as expected according to its highest electron deficient character compared to the rest of the substrates. On the contrary, TCNB was the one to show the lowest (measurable) affinity. It is worth mentioning that the ${ }^{1} \mathrm{H}$ NMR titrations of this substrate showed that, together with the protons at the pyrene, the protons due to the phenyl ring at the phenylacetylide ligands also showed an upfield shifting of the signal, thus indicating that for TCNB, the interaction of the guest with the complex could be simultaneously produced in the inner part of the folder formed by the two pyrene-imidazolylidene ligands, and also with the phenylacetylide ligands.

Table 1. Binding constants of $2-n \mathrm{Bu}$ and $4-n \mathrm{Bu}$ with different electron-deficient arenes (DMSO, 25ㅇ). ${ }^{\mathrm{a}}$

\begin{tabular}{lllll} 
& & & $\mathrm{K}_{11}, \mathrm{M}^{-1}$ & \\
\cline { 4 - 5 } Entry & Guest & Solvent & $2-n \mathrm{Bu}$ & $4-n \mathrm{Bu}$ \\
\hline 1 & TCNB & DMSO- $_{6}$ & $1 \pm 0.5^{\mathrm{b}}$ & n.d. $^{\mathrm{c}}$ \\
2 & TNFLU & DMSO- $_{6}$ & $9 \pm 1$ & $22 \pm 1$ \\
3 & TNFLU & CDCl $_{3}$ & $21 \pm 1$ & $47 \pm 1$ \\
4 & NTCDA & DMSO- $_{6}$ & $8 \pm 1$ & $10 \pm 1$ \\
5 & pyrene & DMSO- $_{6}$ & $\approx 0$ & $\approx 0$ \\
\hline
\end{tabular}

${ }^{a} K_{11}$ values calculated by global nonlinear regression analysis. ${ }^{[16 a, 17]}$ Titrations were carried out at $298 \mathrm{~K}$, using constant concentrations of host. ${ }^{b}$ For this case, the curve-fitting program generates a more precise value of $0.8 \pm 0.1 \mathrm{M}^{-1}$. However, the binding is very weak, so the fitting is based only on the early part of the binding, with less than $50 \%$ of the complex formed. Accordingly, for this specific case we prefer to give a value of $1 \pm 0.5$ to this constant. ${ }^{c} n . d .=$ not determined; $\Delta \delta$ were too low to make an accurate estimation of the constant.

In addition to the ${ }^{1} \mathrm{H}$ NMR titrations, we also evaluated the affinity of hosts $2-n \mathrm{Bu}$ and $4-n \mathrm{Bu}$ with the different electron deficient aromatic guests by mass spectrometry. ESI-MS is among the most versatile and widespread techniques for this purpose, because it allows to gently transfer noncovalent complexes from solution to gas phase..$^{[18]}$ The electrospray mass spectra (ESI-MS) of complexes 2-nBu and 4-nBu with an excess of the different guests and in the presence of $\mathrm{Nal}$, showed prominent peaks formulated as $[\mathrm{M}+\mathrm{I}+\mathrm{X}]^{-}$in the negative mode (with $\mathrm{X}$ being the corresponding guest molecule). These results are in agreement with the 1:1 host:guest stoichiometry found by the NMR titrations. We next addressed the potential of the ESI technique to qualitatively unravel the relative binding affinities of $4-n \mathrm{Bu}$ towards the whole set electron deficient arenes via competitive ESI-MS experiments. ESI-MS-based methods are known to be very useful for quantitatively evaluating host:guest binding events. $^{[18 \mathrm{~b}, 19]}$ In competition ESI-MS experiments, the ESI mass spectrum of a selected host is investigated in the presence of a set of potential guests, so that identification and quantification of different host-guest complexes are simultaneously measured. The competitive ESI mass spectrum (negative scan mode) taken from solutions of 4- $n \mathrm{Bu}$ and a three-fold excess of guests in $\mathrm{CH}_{2} \mathrm{Cl}_{3} / \mathrm{CH}_{3} \mathrm{CN}$ is shown in Figure 3. In this negative ESI mass spectrum, we observed the formation of the supramolecular complexes formed between $4-n \mathrm{Bu}$ and all the substrates used. Ion abundances indicate the higher tendency of TNFLU and NTCDA to bind with 4-nBu, while adduct with TCNB shows a much less intense peak as a consequence of its lower affinity, in agreement with the results obtained by the NMR methods.

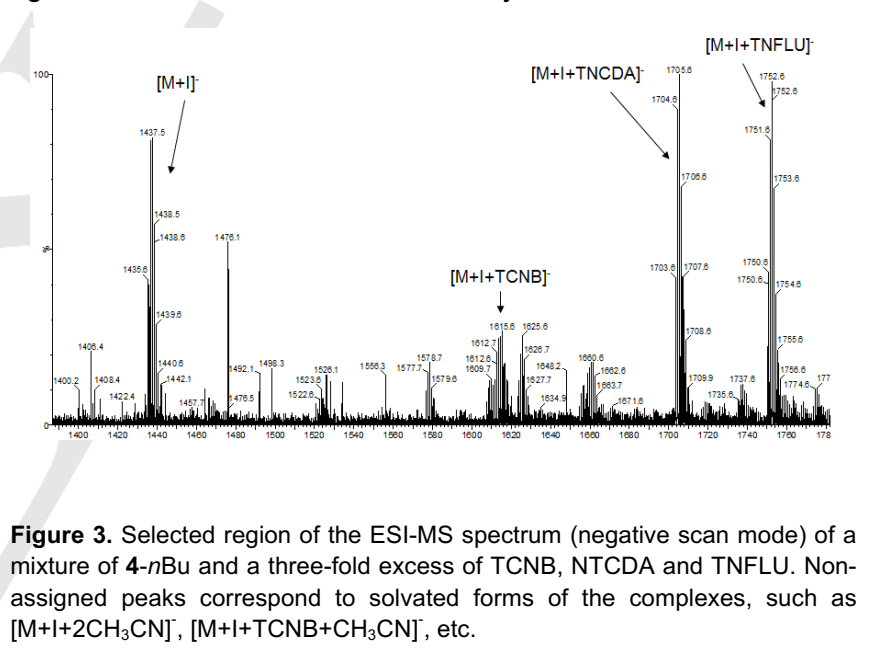

We were able to obtain single crystals of $2-n \mathrm{~B}$ u suitable for X-ray diffraction analysis from a DMSO- $d_{6}$ solution containing TCNB. The resulting structure showed the co-crystallization of $2-n \mathrm{Bu}$ and TCNB (Figure 4). The asymmetric unit cell contained one molecule of 2-nBu and one molecule of TCNB, although with $50 \%$ occupancy at each side of the metal complex. The structure also showed one molecule of DMSO trapped inside the pyrene-based folder of the metal complex. The metric parameters of the molecule are very similar to those shown by molecule $2-n \mathrm{Bu}$ in Figure 1. For example, the $\mathrm{Pt}-\mathrm{C}$ (carbene) bond distances are 2.040 and $2.024 \AA$. The average angle established between the pyrene-imidazolylidene and the coordination plane of the molecule is $70.47^{\circ}$, thus slightly larger than the same parameter in the structure of $2-n \mathrm{Bu}$ depicted in Figure 1 . The angle established between the two NHC ligands is $92.10^{\circ}(13)$ (taken as the measurement of the $\mathrm{C}(1)-\mathrm{Pt}(1)-\mathrm{C}(4)$ angle), which is almost identical to the related angle shown for the structure of $2-n \mathrm{Bu}$ shown in Figure $1\left[\mathrm{C}(1)-\mathrm{Pt}(1)-\mathrm{C}(4) 92.00(16)^{\circ}\right]$. Similarly, the 
angle established by the two phenylacetylide ligands are very similar in the structures of $2-n \mathrm{Bu}$ with and without the tetracyanobenzene guest $\left(88.86^{\circ}\right.$ and $86.99^{\circ}$, respectively). These parameters indicate that the orientation of the ligands is rather rigid, with little adaptation to favour the interaction with the guest. The most significant feature of the structure is the presence of the molecules of TCNB, which show clear $\pi-\pi$ stacking interactions with one of the pyrene walls and one phenyl ring of a phenylacetylide ligand, with interplanar distances of 3.425 and $3.443 \AA$, respectively. This interaction by the two faces of the molecule was already predicted by the NMR titrations (vide supra), although the overall stoichiometry of the adduct formed is $1: 1$, considering the $50 \%$ occupancy of each TCNB molecule. Another interesting feature of the structure, is that each molecule of tetracyanobenzene is trapped by two host molecules, showing an optimal assembly in which the trapping of the molecule of TCNB is alternated by pairs of molecules forming square cages by the combination of two pairs of phenylacetylenes and two pairs phenanthrophenazine fragments. This arrangement is shown in Figure 5.

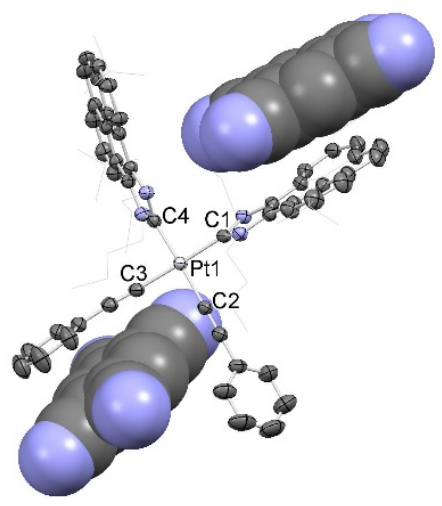

Figure 4. Molecular structure of complex 2-nBu: TCNB. Ellipsoids at $50 \%$ of probability. Hydrogen atoms and solvent (DMSO) omitted for clarity. Tert-butyl groups shown as wireframes for clarity. Two molecules of tetracyanobenzene shown as space-filling diagrams. Selected bond distances $(\AA)$ and angles $\left({ }^{\circ}\right)$ : $\mathrm{Pt}(1)-\mathrm{C}(1)$ 2.040(3), $\mathrm{Pt}(1)-\mathrm{C}(4)$ 2.024(3), $\mathrm{Pt}(1)-\mathrm{C}(2)$ 2.010(3), $\mathrm{Pt}(1)-\mathrm{C}(3)$ 1.990(4), C(1)-Pt(1)-C(4) 92.10(13), C(2)-Pt(1)-C(3) 88.86(12).

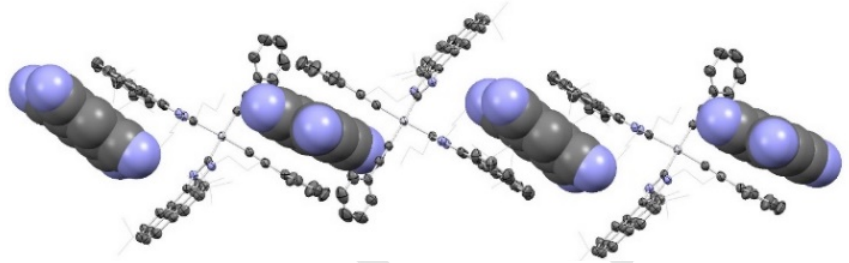

Figure 5. Crystal packing of complex 2-nBu + TCNB. The array of molecules is represented along the $c$ axis.

\section{Conclusions}

In summary, we prepared a series of organometallic folders (OMFOs) for the recognition of aromatic substrates using the cavity formed by the cis-oriented polyaromatic-based ligands. As shown by their molecular structures, these molecules tend to not leave empty the void space formed by the folder. The molecules were tested in the recognition of aromatic substrates, where they showed a selective affinity to bind electron-deficient molecules. Although the host:guest association constants were low, our molecules were able to effectively discriminate between electronrich and electron-deficient aromatic substrates. Our work constitutes the first example of an organometallic folder in molecular recognition. Although the binding affinities found are not as high as those observed for other organic-based molecules tailor-made for the recognition of similar systems, we believe that the simplicity of the preparation of these complexes together with their great potential may soon transform organometallic folders in highly competitive systems. By simply changing the nature of the metal, its oxidation state, the nature of the co-ligands or the neat charge of the complex, we believe that the recognition abilities of metallofolders will be easily tuned, so that selective and highly efficient systems may soon be developed. This, combined with the simplicity of the preparation of our new types of receptors, may trigger the inspiration of researchers in the field of organometallic supramolecular chemistry.

\section{Acknowledgements}

We gratefully acknowledge financial support from MINECO of Spain (CTQ2014-51999-P) and the Universitat Jaume I (P11B2014-02, P11B2015-24). The authors are grateful to the Serveis Centrals d'Instrumentació Científica (SCIC) of the Universitat Jaume I for providing with spectroscopic and X-Ray facilities.

Keywords: Organometallic folder $\cdot$ Platinum $\cdot$ Host-Guest chemistry $\bullet \mathrm{N}$-Heterocyclic carbenes $\cdot$ Supramolecular Chemistry

[1] E. C. Constable, Chemistry \& Industry 1994, 56-59.

[2] a) M. M. J. Smulders, I. A. Riddell, C. Browne and J. R. Nitschke, Chem. Soc. Rev. 2013, 42, 1728-1754; b) E. C. Constable, Coord. Chem. Rev. 2008, 252, 842-855; c) J. R. Nitschke, Acc. Chem. Res. 2007, 40, 103-112; d) P. J. Steel, Acc. Chem. Res. 2005, 38, 243-250; e) F. Wurthner, C. C. You and C. R. Saha-Moller, Chem. Soc. Rev. 2004, 33, 133-146.

[3] a) C. G. Oliveri, P. A. Ulmann, M. J. Wiester and C. A. Mirkin, Acc. Chem. Res. 2008, 41, 1618-1629; b) B. J. Holliday and C. A. Mirkin, Angew. Chem. Int. Ed. 2001, 40, 2022-2043; c) B. Linton and A. D. Hamilton, Chem. Rev. 1997, 97, 1669-1680; d) D. S. Lawrence, T. Jiang and M. Levett, Chem. Rev. 1995, 95, 2229-2260; e) W. Lu, Z. Wei, Z.-Y. Gu, T.F. Liu, J. Park, J. Park, J. Tian, M. Zhang, Q. Zhang, T. Gentle, III, M. Bosch and H.-C. Zhou, Chem. Soc. Rev. 2014, 43, 5561-5593; f) D. L. Caulder and K. N. Raymond, Acc. Chem. Res. 1999, 32, 975-982; g) T. R. Cook, Y.-R. Zheng and P. J. Stang, Chem. Rev. 2013, 113, 734-777.

[4] a) M. Fujita, M. Tominaga, A. Hori and B. Therrien, Acc. Chem. Res. 2005, 38, 369-378; b) M. Fujita, Chem. Soc. Rev. 1998, 27, 417-425; c) R. Chakrabarty, P. S. Mukherjee and P. J. Stang, Chem. Rev. 2011, 111, 6810-6918; d) S. Leininger, B. Olenyuk and P. J. Stang, Chem. Rev. 2000, 100, 853-907; e) P. J. Stang and B. Olenyuk, Acc. Chem. Res. 1997, 30, 502-518; f) A. M. Castilla, W. J. Ramsay and J. R. Nitschke, Acc. Chem. Res. 2014, 47, 2063-2073; g) L. Chen, Q. Chen, M. Wu, F. Jiang and M. Hong, Acc. Chem. Res. 2015, 48, 201-210; h) T. R. Cook 
and P. J. Stang, Chem. Rev. 2015, 115, 7001-7045; i) X. Su and I. Aprahamian, Chem. Soc. Rev. 2014, 43, 1963-1981.

[5] a) P. Ballester, M. Fujita and J. Rebek, Jr., Chem. Soc. Rev. 2015, 44, 392393; b) P. D. Frischmann and M. J. MacLachlan, Chem. Soc. Rev. 2013 42, 871-890.

[6] a) C. J. Brown, F. D. Toste, R. G. Bergman and K. N. Raymond, Chem. Rev. 2015, 115, 3012-3035; b) S. H. A. M. Leenders, R. Gramage-Doria, B. de Bruin and J. N. H. Reek, Chem. Soc. Rev. 2015, 44, 433-448; c) P. Dydio and J. N. H. Reek, Chem. Sci. 2014, 5, 2135-2145; d) T. S. Koblenz, J. Wassenaar and J. N. H. Reek, Chem. Soc. Rev. 2008, 37 247-262; e) M. Raynal, P. Ballester, A. Vidal-Ferran and P. W. N. M. van Leeuwen, Chem. Soc. Rev. 2014, 43, 1660-1733.

[7] a) S. Dong, B. Zheng, F. Wang and F. Huang, Acc. Chem. Res. 2014, 47, 1982-1994; b) K. Ariga, H. Ito, J. P. Hill and H. Tsukube, Chem. Soc. Rev. 2012, 41, 5800-5835; c) B. Chen, S. Xiang and G. Qian, Acc. Chem. Res. 2010, 43, 1115-1124.

[8] A. Galan and P. Ballester, Chem. Soc. Rev. 2016, 45, 1720-1737.

[9] J.-N. Rebilly, B. Colasson, O. Bistri, D. Over and O. Reinaud, Chem. Soc. Rev. 2015, 44, 467-489.

[10] a) C. M. Alvarez, L. A. Garcia-Escudero, R. Garcia-Rodriguez, J. M. MartinAlvarez, D. Miguel and V. M. Rayon, Dalton Trans. 2014, 43, 1569315696; b) Y. Tanaka, K. M. C. Wong and V. W. W. Yam, Angew. Chem. Int. Ed. 2013, 52, 14117-14120; c) H. J. Yoo, C. A. Mirkin, A. G. DiPasquale, A. L. Rheingold and C. L. Sternt, Inorg. Chem. 2008, 47 9727-9729; d) H. Lang, R. Packheiser and B. Walfort, Organometallics 2006, 25, 1836-1850; e) A. M. Brown, M. V. Ovchinnikov and C. A. Mirkin Angew. Chem. Int. Ed. 2005, 44, 4207-4209; f) N. C. Gianneschi, S. H Cho, S. T. Nguyen and C. A. Mirkin, Angew. Chem. Int. Ed. 2004, 43 5503-5507; g) J. B. Diccianni, C. Hu and T. Diao, Angew. Chem. Int. Ed. 2017, DOI: 10.1002/anie.201611572; h) Y. Tanaka, K. M. C. Wong and V. W. W. Yam, Chem. Eur. J. 2013, 19, 390-399; i) T. F. Fu, Y. F. Han L. Ao and F. Wang, Organometallics 2016, 35, 2850-2853; j) B. Doistau, C. Rossi-Gendron, A. Tron, N. D. McClenaghan, L. M. Chamoreau, B Hasenknopf and G. Vives, Dalton Trans. 2015, 44, 8543-8551.

[11] a) C. Mejuto, G. Guisado-Barrios, D. Gusev and E. Peris, Chem. Commun. 2015, 51, 13914-13917; b) N. Sinha, F. Roelfes, A. Hepp, C. Mejuto, E.
Peris and F. E. Hahn, Organometallics 2014, 33, 6898-6904; c) C Segarra, G. Guisado-Barrios, F. E. Hahn and E. Peris, Organometallics 2014, 33, 5077-5080.

[12] a) E. Mas-Marza, J. A. Mata and E. Peris, Angew. Chem. Int. Ed. 2007, 46, 3729-3731; b) S. Gonell, M. Poyatos and E. Peris, Chem. Eur. J. 2014 20,9716-9724; c) A. Prades, E. Peris and M. Alcarazo, Organometallics 2012, 31, 4623-4626; d) H. Valdes, M. Poyatos and E. Peris, Organometallics 2015, 34, 1725-1729; e) S. Gonell, M. Poyatos and E. Peris, Angew. Chem. Int. Ed. 2013, 52, 7009-7013; f) G. Guisado-Barrios, J. Hiller and E. Peris, Chem. Eur. J. 2013, 19, 10405-10411.

[13] E. Peris, Chem. Commun. 2016, 52, 5777-5787.

[14] a) H. Valdes, M. Poyatos, G. Ujaque and E. Peris, Chem. Eur. J. 2015, 21, 1578-1588; b) H. Valdes, M. Poyatos and E. Peris, Inorg. Chem. 2015, 54, 3654-3659.

[15] S. Gonell and E. Peris, ACS Catal. 2014, 4, 2811-2817.

[16] a) P. Thordarson, Chem. Soc. Rev. 2011, 40, 1305-1323; b) K. Hirose, J. Incl. Phenom. Macrocycl. Chem. 2001, 39, 193-209; c) D. B. Hibbert and P. Thordarson, Chem. Commun. 2016, 53, 12792-12805.

[17] A. J. Lowe, F. M. Pfeffer and P. Thordarson, Supramol. Chem. 2012, 24, 585-594.

[18] a) Z. Chen and S. G. Weber, Trac-Trends in Analytical Chemistry 2008, 27, 738-748; b) J. M. Daniel, S. D. Friess, S. Rajagopalan, S. Wendt and R. Zenobi, Int. J. Mass. Spectrom. 2002, 216, 1-27; c) C. A. Schalley, Int. J. Mass. Spectrom. 2000, 194, 11-39.

[19] a) N. K. Beyeh, M. Goeth, L. Kaufmann, C. A. Schalley and K. Rissanen, Eur. J. Org. Chem. 2014, 2014, 80-85; b) N. K. Beyeh, D. P. Weimann, L. Kaufmann, C. A. Schalley and K. Rissanen, Chem. Eur. J. 2012, 18, 5552-5557; c) H. Mansikkamaki, C. A. Schalley, M. Nissinen and K. Rissanen, New J. Chem. 2005, 29, 116-127; d) S. Ruiz-Botella, P. Vidossich, G. Ujaque, C. Vicent and E. Peris, Chem. Eur. J. 2015, 21, 10558-10565; e) C. A. Schalley, Mass Spectrom. Rev. 2001, 20, 253309; f) E. C. Kempen and J. S. Brodbelt, Anal. Chem. 2000, 72, 54115416; g) S. M. Blair, E. C. Kempen and J. S. Brodbelt, J. Am. Soc. Mass Spectrom. 1998, 9, 1049-1059. 
WILEY-VCH

\section{FULL PAPER}

A series of platinum complexes with cis-oriented polyaromatic $\mathrm{N}$ -

heterocyclic carbene ligands behave as metallofolders, and can be used a receptors of electrondeficient aromatic substrates.
Daniel Nuevo, Sergio Gonell, Macarena Poyatos and Eduardo Peris*

Page No. - Page No.

Title 